\title{
Role of Diagnostic Laparoscopy in Evaluation of Infertile Women
}

\author{
AKHTARUNNESSA ${ }^{1}$, T.A.CHOWDHURY ${ }^{2}$, ISMAT ARA ${ }^{3}$, MD.LUTFUL KARIM GAZI ${ }^{4}$, BANIKA BISWAS $^{5}$
}

\begin{abstract}
:
Aims: To find out the magnitude of different types of pelvic pathologies female infertility by laparoscopy.

Methods: Nine hundred infertile women who had undergone infertility evaluation by laparoscopy to see the pelvic pathology or evaluation of pelvic organs at a private infertility clinic at Dhaka between January 2002 and October 2004 were studied. Assessment of these patients was carried out carefully before starting the endoscopic procedures. A full history was taken which was followed by thorough general, abdominal and pelvic examinations then Laparoscopy was performed under general anaesthesia .
\end{abstract}

Results: The mean age ranged from 18 to 42 years. Among them 612 (68\%) patients were aged between 21 to 30 years. Six hundred and seven (67.44\%) patients had primary infertility and 293 (32.56\%) had secondary infertility.

Laparoscopic findings showed that 610 (67.78\%) patients had normal uterus while 390 (31.22\%) had abnormalities of uterus. Among them 76 (8.4\%) had uterine myomas.

Five hundred and seventy four (64\%) had normal tubes, 70 (7.8\%) had some form of peritubal adhesions and 196 (21.78\%) had tubal block, either unilateral or bilateral.

Six hundred and sixty seven (74.11\%) patients had normal pelvic peritoneum, 148 (16.44\%) had pelvic adhesions probably from pelvic inflammatory diseases and $85(9.45 \%)$ had frank endometriosis.

Two hundred and eighty nine (32.11\%) had normal ovaries, 370 (41.11\%) had polycystic ovaries (PCO), 109 (12.11\%) had periovarian adhesions 72 (8\%) patients had simple ovarian cysts while 19 (2.11\%) had endometriotic (chocolate) cysts.

Conclusion: Ovarian pathology was the highest pelvic abnormality (41\%) followed by tubal pathology 36\% and uterine pathology 32\%.

Key words: Diagnostic laparoscopy, infertile women.

Introduction:

Laparoscopy is a reliable procedure which improves diagnostic accuracy in pelvic disorders and can reveal information which may make laparotomy unnecessary. ${ }^{1}$

Diagnosis of endometriosis is usually based on laparoscopic findings. ${ }^{2}$ The timing of laparoscopy is one of the key aspects of the discussion of the pace at which the couple and the practitioner feel the investigation should proceed. In a young couple with a negative history, it is usually offered after all other tests are completed and discussed; in older couples or if the history suggests a pelvic factor, it is often indicated as one of the primary methods of evaluation. ${ }^{2}$

\section{Objectives:}

To determine the role of diagnostic laparoscopy in the evaluation of female infertility in a private hospital

1. Assistant Professor, Obstetrics \& Gynaecology, Medical College for Women \& Hospital, Uttara, Dhaka.

2. Professor \& Head, department of Obstetrics \& Gynaecology, BIRDEM, Dhaka.

3. Professor, Obstetrics \& Gynaecology, Jahurul Islam Medical College.

4. FCPS Part-II student, Obstetrics \& Gynaecology.

5. FCPS Part-II student, Obstetrics \& Gynaecology. 
setting and to find out the poportion of different types of pelvic pathologies and conditions in women of infertility.

\section{Methodology:}

This is a retrospective study for cases of diagnostic laparoscopy that had been carried out at a private infertility clinic during the period January 2002 to December 2004.

Assessment of these patients was carried out carefully before starting the endoscopic procedures. A full history was taken which was followed by thorough general, abdominal and pelvic examinations.

Laparoscopy was performed under general anaesthesia with controlled ventilation. The patients were placed in a modified lithotomy position and then $15^{\circ}$ to $20^{\circ}$ Trendelenberg tilt was employed. The bladder was catheterized and a pelvic examination was carried out. The uterine canula was secured to the cervix by means of a single toothed tenaculum. After induction of proper pneumoperitoneum with $\mathrm{CO}_{2}$, laparoscopy was performed using an intra-umbilical entry. Multiple punctures technique was employed and the peritoneal cavity was inspected thoroughly.

Methylene blue dye solution was used for the observation of tubal patency with spill of dye in peritoneal cavity. Then the instruments were removed, pneumoperitoneum was deflated, and the umbilical incision was closed with 3-0 dexon suture.

\section{Results:}

Nine hundred cases were included in this study. The age ranged from 18 to 42 years.

Table I shows the age of the patients. Nine patients (1\%) were between the age of 18 to 20 years. Six hundred and twelve patients (68\%) were aged between 21 to 30 years. The age of the other 278 patients (30.9\%) ranged from 31 to 40 years while only 1 patient $(0.1 \%)$ was aged 42 years.

Table-I

Age of patients

\begin{tabular}{lcc}
\hline Age of patients & Number of patients & Percentage \\
\hline 18 to 20 years & 9 & $1 \%$ \\
21 to 30 years & 612 & $68 \%$ \\
31 to 40 years & 278 & $30.9 \%$ \\
42 years & 1 & $0.1 \%$ \\
\hline
\end{tabular}

Fig. I shows the type of infertility, primary or secondary. The infertility of 607 patients (67.44\%) was primary while 293 patients (32.56\%) had secondary infertility.
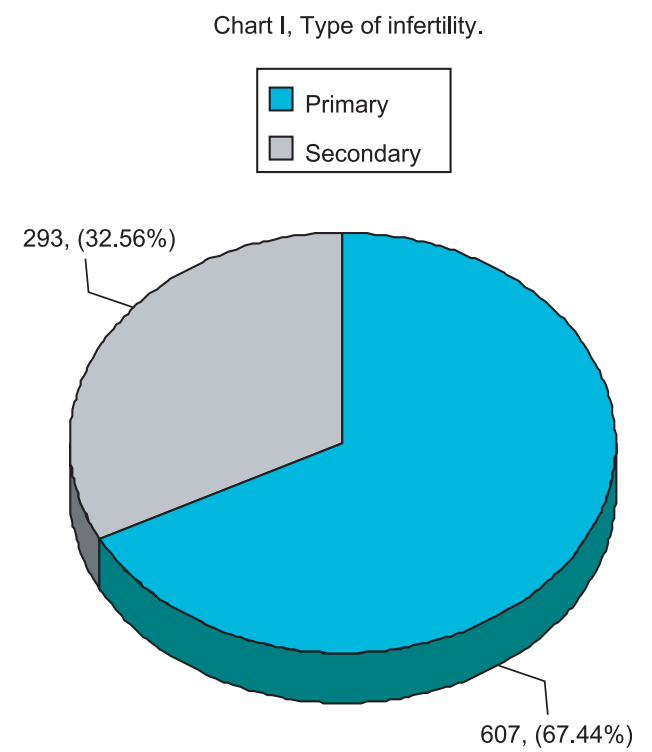

Table II shows uterine pathology. Six hundred and ten patients (67.78\%) had normal uterus. One hundred and one patients (11.22\%) had enlarged uterus while the uterus of 63 patients ( $7 \%$ ) had smaller than normal sized uterus.

Among them 76 (8.4\%) had myomas, the mobility of the uterus was restricted in 111 patients (12.33\%), congenital anomaly in the form of unicornuate and bicornuate uterus was seen in 5 patients (0.56\%), and the uterus could not be visualised due to gross adhesion in 10 cases (1.1\%).

Table-II

Uterine pathology.

\begin{tabular}{lcc}
\hline $\begin{array}{l}\text { Laparoscopic } \\
\text { findings }\end{array}$ & $\begin{array}{c}\text { Number of } \\
\text { patients }\end{array}$ & Percentage \\
\hline Normal in size & 610 & $67.78 \%$ \\
Smaller than normal & 63 & $7 \%$ \\
Enlarged Myoma & 76 & $8.4 \%$ \\
$\quad$ Adenomyosis & 25 & $2.82 \%$ \\
Restricted mobility & 111 & $12.33 \%$ \\
Unicornuate/bicornuate & 5 & $0.56 \%$ \\
Not seen due to adhesions & 10 & $1.11 \%$ \\
\hline
\end{tabular}

Table III shows tubal pathology. Five hundred and seventy four patients (74\%) had normal tubes. One hundred and two (11.33\%) had some form of peritubal adhesion. One hundred and ninety six patients 
(21.78\%) had tubal block. Among them 100 patients (11.11\%) had unilateral block of whom 66 (7.33\%) had cornual block and 34 (3.77\%) had fimbrial block.

Ninety six patients (10.67\%) had bilateral tubal block and among them 56 (6.2\%) had cornual block and 40 (4.44\%) had fimbrial block.

Seventeen patients (1.89\%) had hydrosalpinx and 13 (1.44\%) had tubo-ovarian mass.

The tubes could not be visualised in 32 cases (3.56\%) due to gross adhesions.

Table-III

Tubal pathology.

\begin{tabular}{lccc}
\hline $\begin{array}{l}\text { Laparoscopic } \\
\text { findings }\end{array}$ & $\begin{array}{c}\text { Number of } \\
\text { patients }\end{array}$ & Percentage \\
\hline Normal tubes & 666 & $74 \%$ \\
\multicolumn{2}{l}{$\begin{array}{l}\text { Peritubal adhesions } \\
\text { Tubal block }\end{array}$} & 102 & $11.33 \%$ \\
& Unilateral & 100 & $11.11 \%$ \\
Hydrosalpinx & Bilateral & 96 & $10.69 \%$ \\
Tubo-ovarian mass & 17 & $1.89 \%$ \\
Not seen due to & Right & 6 & $1.44 \%$ \\
adhesions & Left & 9 & $0.67 \%$ \\
& Both & 17 & $1 \%$ \\
\hline
\end{tabular}

Table IV shows peritoneal pathology. Six hundred and sixty seven patients $(74.11 \%)$ had normal pelvic peritoneum, 148 (16.44\%) had pelvic adhesions from PID and 85 patients (9.45\%) had endometriosis.

Table-IV

Peritoneal pathology.

\begin{tabular}{lcc}
\hline Laparoscopic findings & $\begin{array}{c}\text { Number of } \\
\text { patients }\end{array}$ & Percentage \\
\hline Normal & 667 & $74.11 \%$ \\
Pelvic adhesions & 148 & $16.44 \%$ \\
Endometriosis & 85 & $9.45 \%$ \\
\hline
\end{tabular}

Table V shows ovarian pathology. Two hundred and eighty nine patients (32.11\%) had normal ovaries. One hundred and nine (12.11\%) had peri-ovarian adhesions, $370(41.11 \%)$ had polycystic ovaries (PCO), 5 patients $(0.56 \%)$ had small ovaries. Thirteen patients $(1.44 \%)$ had tubo-ovarian mass, $72(8 \%)$ had simple cysts while 19 patients $(2.11 \%)$ had chocolate cysts. Gonadal dysgenesis was found in $6(0.67 \%)$ and highly corrugated ovaries in 17 patients (1.89\%).
Table-V

Ovarian pathology.

\begin{tabular}{lcc}
\hline Laparoscopic findings & Number & Percentage \\
\hline Normal & 289 & $32.11 \%$ \\
Peri-ovarian adhesions & 109 & $12.11 \%$ \\
PCO & 370 & $41.11 \%$ \\
Small & 5 & $0.56 \%$ \\
Tubo-ovarian mass & 13 & $1.44 \%$ \\
Simple cyst & 72 & $8 \%$ \\
Chocolate cyst & 19 & $2.11 \%$ \\
\hline
\end{tabular}

\section{Discussion:}

Since 1960 when safe technique for induction of pneumoperitoneum was developed and fibre optic system for light transmission became available, laparoscopy has gained widespread popularity in gynaecologic practice. It has been used to diagnose unknown problems, to follow the course of a known disease and to modify therapy. Furthermore, some surgical procedures such as lysis of adhesions, tubal sterilization have been performed through laparoscopy. Laparoscopic procedures are less invasive, more convenient, and more precise for diagnosis of subfertility in women ${ }^{9}$. So laparoscopy has achieved widespread use as a valuable diagnostic aid in gynaecology ${ }^{3}$.

In this retrospective study laparoscopy was done in 607 patients with primary infertility (67.44\%) and 293 patients with secondary infertility (32.96\%). Nabil et al in a study showed primary infertility in $29.3 \%$ patients and secondary infertility in $59.6 \%$ cases $^{1}$. Whereas Haider et al in a study of 200 subfertile patients found $66 \%$ with primary and $33 \%$ with secondary infertility which is in conformity with the present study ${ }^{9}$.

Laparoscopy is very helpful in discovering unsuspected pelvic pathology specially pelvic adhesions ${ }^{4}$. It is superior in evaluation of tubal obstruction, pelvic adhesions and endometriosis than other methods ${ }^{5}$. It has permitted the development of concomitant accessory therapeutic procedures, thus defining the best treatment strategy for the infertile couples ${ }^{10}$.

In the current study pelvic adhesions were found in $16.44 \%$ cases. This is noticeably less than Nabil et al who found pelvic adhesions in $35.23 \%$ patients in 1994, and $50 \%$ found in 1987 by Chang et al ${ }^{5}$. Pereira et al found pelvic adhesions in $18.6 \%$ patients ${ }^{10}$.

Laparoscopy is an essential step prior to tubal surgery as it may not only preclude the unnecessary operation but may also provide essential information regarding the nature and extent of future surgery ${ }^{6}$. Because of 
potential diagnostic and therapeutic benefits, patients with unexplained infertility and normal HSG findings should undergo diagnostic laparoscopy prior to ART ${ }^{11}$.

In this study tubal patency test showed the test was positive in both sides in $74 \%$ cases. There was unilateral block in $11.11 \%$ and bilateral block in $10.69 \%$. In 1995 Adulesi et al found that $52 \%$ patients had both tubes patent and $48 \%$ patients had tubal block $^{7}$. Nabil et al in 1994 showed $46.06 \%$ of studied cases had bilateral tubal patency ${ }^{1}$. Pereira et al found normal tubal patency in 53\% cases, unilateral obstruction in $25.3 \%$, and bilateral obstruction in $20.5 \%$ cases $^{10}$.

Pelvic endometriosis was found in $9.45 \%$ cases which is higher than Nabil et al who showed the incidence was $3.69 \%$ and Adulesi et al at 1.9\%. Pereira et al found $24.4 \%$ cases of endometriosis which is much higher.

In this study the incidence of PCO was $41.11 \%$ which is noticeably higher than the study of Nabil et al (8.05\%) and Adelusi et al (6.7\%). In another study Aziz et al found $15.6 \%{ }^{12}$, which is also much lower than the present study. This disparity may be due to the fact that many of the patients were referred to this centre for laparoscopy who failed ovulation induction.

Ovarian cyst was found in $8 \%$ cases which is also higher than Nabil et al (3.89\%) and slightly higher than Adelusi et al who found that $7.7 \%$ of their patients had ovarian cysts.

\section{Conclusion:}

Infertility by itself does not threaten physical health but has strong impact on the psychological and social well being of couples. In developing countries like Bangladesh, couples, especially the female, are tormented from various quarters of society for this condition which is very distressing. So effort should be made to help them by establishing the cause of infertility and managing accordingly. Laparoscopy is an important and well established procedure which can help these patients by diagnosing the exact cause of infertility in time. It is also cost effective in the initial management of young women with infertility ${ }^{13}$.

\section{Acknowledgement:}

The author wishes to thank the Consultants and staff of Farida Clinic and Infertility Management Centre for allowing to study the case notes of patients under their care.

\section{References:}

1. Nabil,M. El-Tabbakh. Amin,A.M. (1994): Diagnostic laparoscopy in gynaecological problems : a retrospective study. OBGYN.net.
2. Eskandari, N. and Cadieux, M., (2003): Reproductive Endocrinology and Infertility, in Current Obstetric \& Gynaecologic Diagnosis \& Treatment, $9^{\text {th }}$ Ed., eds: DeCherney, A.H. and Nathan, L., Lange/McGraw Hill, p 986.

3. Morales, A. and Murphy, A. (1992) : Operative laparoscopy in gynaecology. Curr. Probl. Obstet. Gynecol. Fertil., XV(2) : 73.

4. Youngblood, J.P (1992) : Advanced surgical techniques in obstetrics and gynaecology. Correspondence released by the Council on Resident Education in Obstetrics and Gynaecology, $12^{\text {th }}$ Ed., St. S.W. Washington, D.C., p 409.

5. Witt, B.R. (1991) : Pelvic factor and fertility workup of the infertile women. Infertil. Reprod. Med. Clin. N. Am. 2(2) : 371- 390.

6. Chang,Y.S. Lee,J.Y. Moon, S.Y. and Kim, J.G. (1987) : Diagnostic laparoscopy in disorders. Asia Oceania J. Obstet. Gynaecol., 13(1) : 29-34.

7. Adelusi,B. Al-Nuaim,L. and Makanjuola,D. (1995) : Diagnostic tubal patency. Fertil. Steril., 63(5) : 1016-1019.

8. Nezhat,C.R. Nezhat,F.R. Luciano,A.A. Siegler,A.M. Metzger,D.A. Nezhat,C.H. (1995) : Operative Gynecologic Laparoscopy \& Hysteroscopy. Principles of Laparoscopy, p 40.

9. Haider,G. Rani,S. Talpur,S. Zehra,N. Munir,A. (2010) : Laparoscopic evaluation of female infertility. J.Ayub Med.Coll. Abbottabad., 22(1):136-8.

10. Pereira,N.R. Leite,M.H. Ribeiro,R.N. Passarinho,R.M. Castro,M.G. Matias,S.M. (2010) : Laparoscopy in the decision of treatment strategy for the infertile couple. Rev.Bras.Ginecol.Obstet., 32(9): 441-6.

11. Tsuji,I. Ami,K. Miyazaki,A. Hujinami,N. Hoshiai,H. (2009) : Benefit of diagnostic laparoscopy for patients with unexplained infertility and normal hysterosalpingography findings. Tohoku J.Exp.Med. 219(1) : 39-42.

12. Aziz,N. (2010) : Laparoscopic evaluation of female factors in infertility. J.Coll.Physicians.Surg.Pak. 20(10) : 649-52.

13. Moayeri,S.E. Lee,H.C. Lathi,R.B. Westphal, L.M. Milki, A.A. Garber,A.M. (2009) : Laparoscopy in women with unexplained infertility: a cost effective analysis. Fertil.Steril. 92(2) : 471-80. 